\title{
Unusual Cause of Hemiparesis in a Child
}

\section{Abbas A*}

Senior Clinical Fellow, Paediatrics and Neonatology, The Royal London Hospital, London, United Kingdom

"Corresponding author: Abbas A, Senior Clinical Fellow, Paediatrics and Neonatology, The Royal London Hospital, London, United Kingdom, E-mail: syedabbas.asad@gmail.com

Citation: Abbas A (2016) Unusual Cause of Hemiparesis in a Child. J Case Rep Stud 4(2): 205. doi: $10.15744 / 2348-9820.4 .205$

Received Date: March 18, 2016 Accepted Date: April 16, 2016 Published Date: April 19, 2016

\section{Description}

A 12 years old child presented to a tertiary hospital in India with weakness and poor growth of the left side of the body since birth (Figure 1). He was born at full gestation through a normal delivery and cried after a few minutes of birth following manual stimulation. The antenatal period was uneventful. There was no history of head trauma or any serious neurological illness after birth. He had a normal intellect with a mild speech delay; there was no history of seizures. Examination revealed a left complete hemiparesis and spasticity with atrophy of the muscles of the left side. CT scan revealed an intracranial cyst in the right hemisphere with a well-defined border and central attenuation the same as CSF, communicating with subarachnoid space and ventricle (Figure 2).

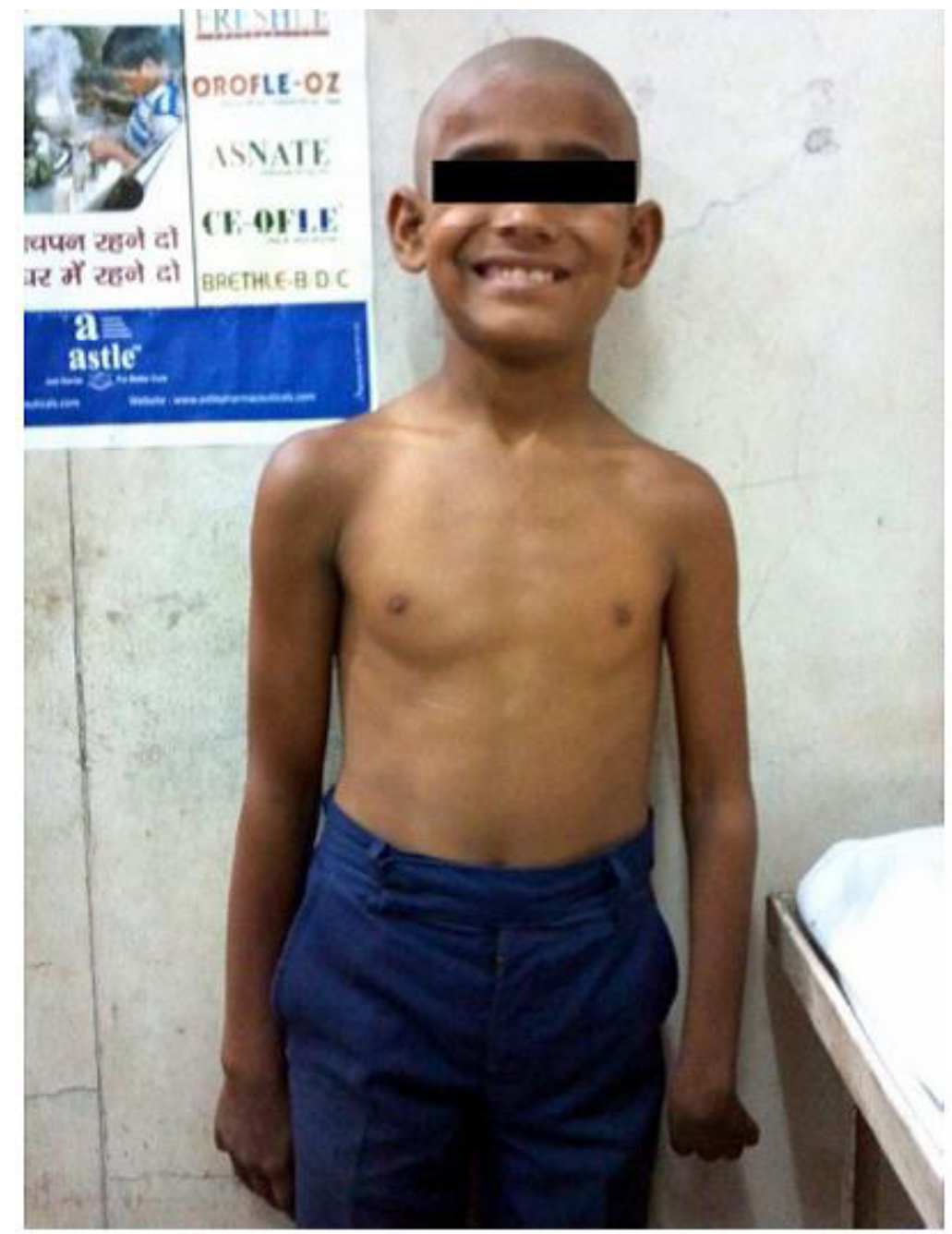

Figure 1: 12 year old child with left complete hemiparesis with hemi-atrophy of left side of the body 


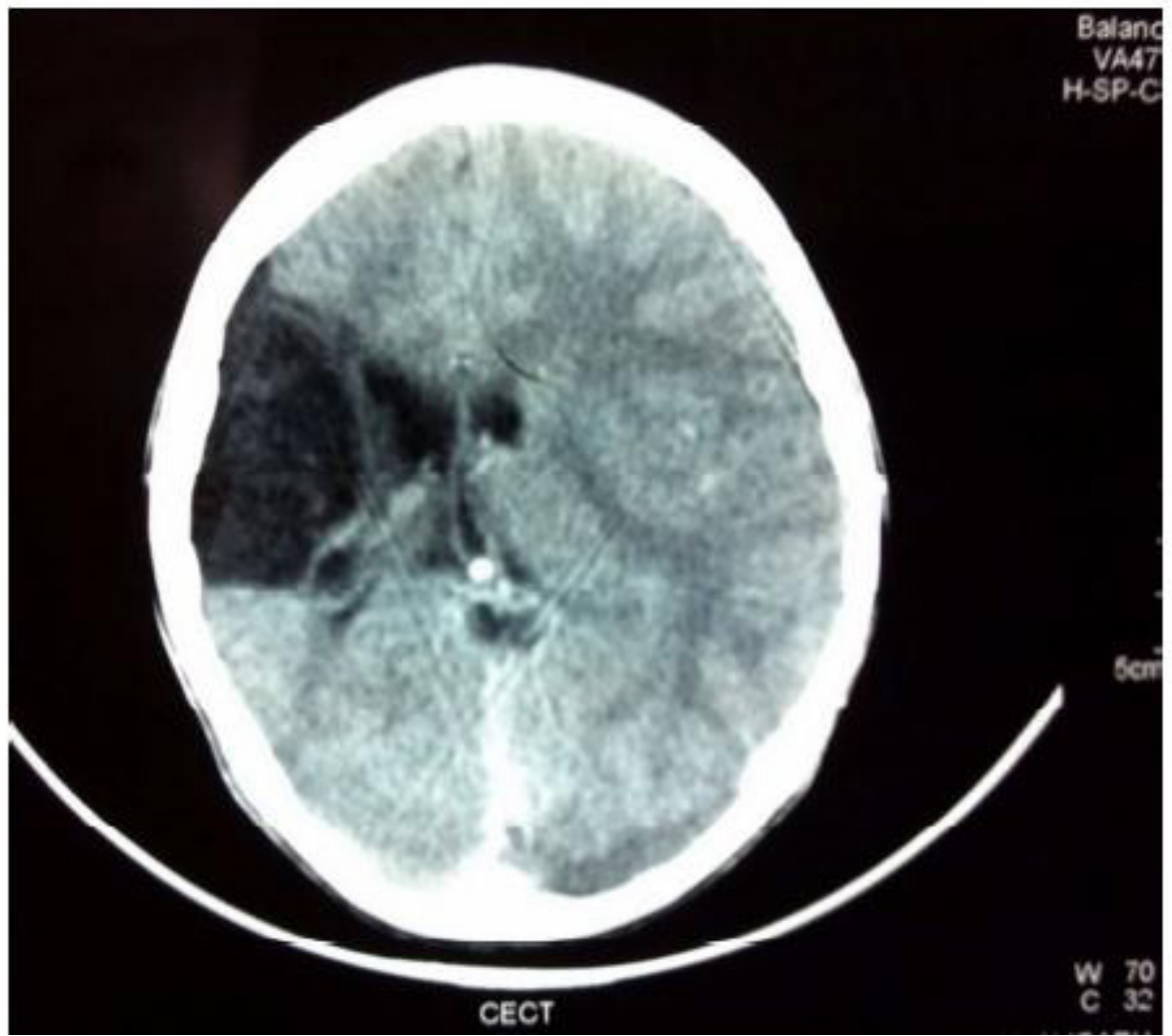

Figure 2: Porencephalic cyst in the right hemisphere

Porencephaly is a rare condition, defined as a cystic lesion of the brain due to an encephaloclastic insult, lined by white matter, which communicates with the ventricules and/or the subarachnoid space. These cysts are mostly congenital and usually a result of perinatal cerebral ischaemia, trauma, infection or antenatal intraparenchymal haemorrhage 1) As there is a wide variation in the location and size of the cysts, the clinical manifestations range from normal to profound impairment. Signs and symptoms usually appear soon after birth with seizures and rigidity seen early 2) Mental retardation, developmental delay and motor deficits are also common. Head circumference is usually normal, however sometimes formation of synechiae within the cyst leads to one way valve effect leading to hydrocephalus. Management is supportive, and prognosis depends upon the size and location of the cyst.

\section{References}

1. Grant EG, Kerner M, Schellinger D, Borts FT, McCullough DC, et al. (1982) Evolution of porencephalic cysts from intraparenchymal hemorrhage in neonates: sonographic evidence. AJR Am J Roentgenol 138: 467-70.

2. Shimizu M, Maeda T, Izumi T (2012) The differences in epileptic characteristics in patients with porencephaly and schizencephaly. Brain Dev 34: 546-52.

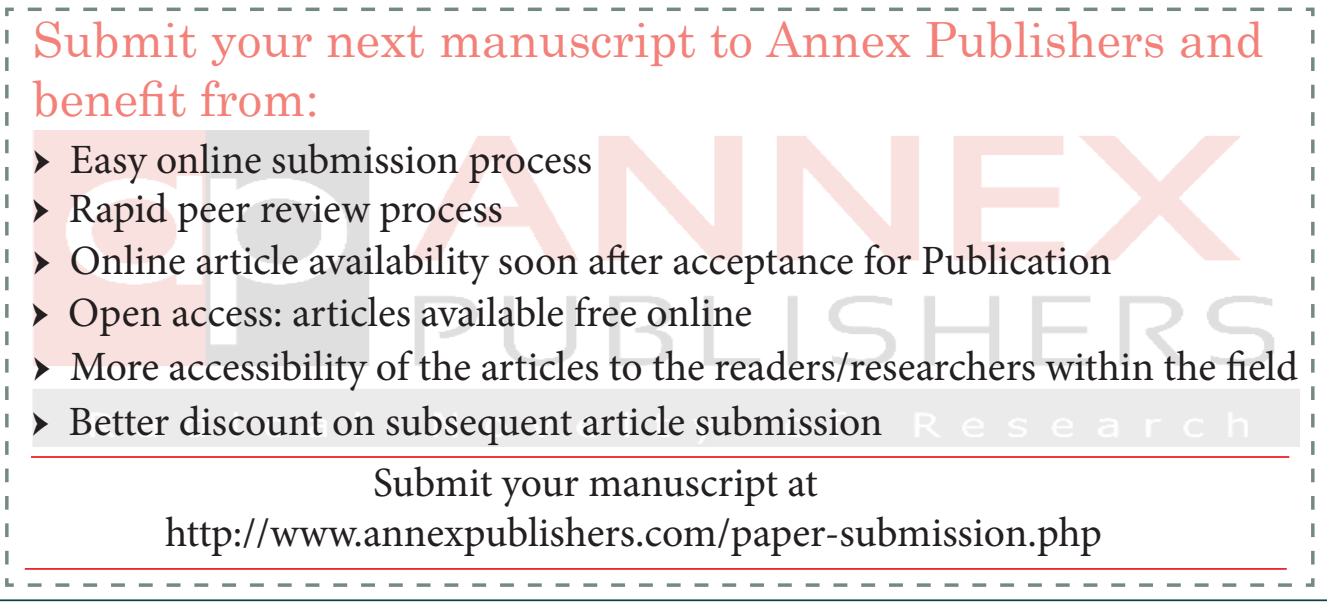

